\title{
Yersinia enterocolítica: su rol como agente de diarrea aguda en lactantes chilenos
}

\author{
Drs.: V. Prado J., J. Cohen V.
}

\begin{abstract}

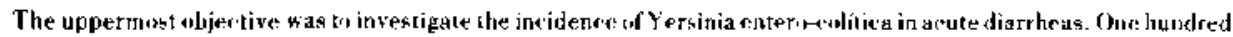
infants below 2 years, with actute diarrhea in Children (aluo Mackemi Hospital were sludied.

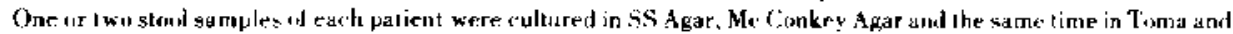
Deindriek selextive medium. wich was incubated during 21 days at 4 " $C$.

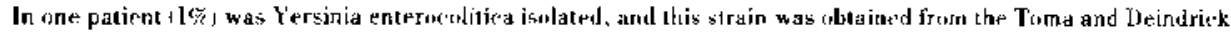

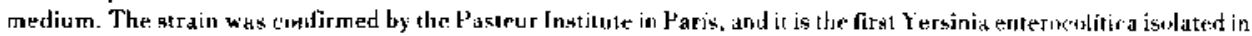
childrenx's disases in our country.

The elinis whacteristic of the Yersinia iufertion didnt shew any relevant penture.
\end{abstract}

Yersinia entereceslitica ha tmergide en lens últimus años reımu un barle rio patugenn impurlante, con un gran impacto en inlececones gastru inte tinales en paises europecos, en Fistados Unidos de Norteamérióa y en Canadá. 11, 12:

Era cenescida desde antiguo, dentrodel gruporle. las Pasteurellas, pero a partir rlẹ añu 1970 fue inclu ida oflecialenentedentrode la lamilia Entermbarteriacerae con la que tiene mayor atinidad de anuerd" al análision de sus ácidus nucleicuss. 31 . 1.41

Primordialmente es patógeno de animales inferiores, pero es capaz de transmitirse al hombre provocando diversas patolegias, como enteronolitis, linfadenitis mesentérica, septicemia y focus supurados como artritis, meningitis y abcesus en diferentes parénquimas, comunicándose cada vez con mayor frecuencia su hallazgo en este tipe de cuadros, destacando el aislamiento en broles de gastroenteritis ell niños. $13 ., 10.101$

En Latinnamírica silo se han efertuado hallazgos ocasionales y han sido comunicaders dos casos en adultos en Brasil. 'r: Es posible que esto se deba a que no se piensa en este agernte a no se utiliza la melordologia ader uada para huscarlar.

En nuestro pais, en 1976, Alonso y colaborado-

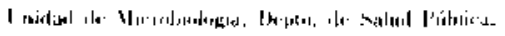

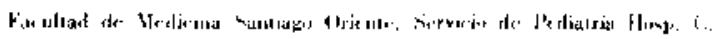

Warkerrina. res, 19. cumunicaron el aislamiento de Yersinia enteruculítica en ratones silvestres de la zona de Valdivia con una frecuencia de un $3 \%$, lo cual constituyá la evidencia de la presencia de este bacterio en nuestro medio y hace sospechar que puede tener una mayor difusion a nivel de animales inferiores y eventualmente en el humbre.

Corroborando este hallazgon, últimamente ha

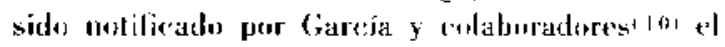

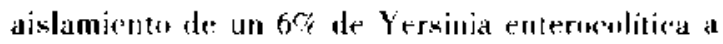
partir de apeindices de personas adulas interyenidas parr cuadros de abdomen agudo en nuestro país.

Cinn las evidencias anteriores tle la existenciad d. Yersinia enterosectitica en Chile, el interís de: nuestro trabajo estuwo dirigito a averiguar si a este bacterio enterouatongeno le correspondia algutn rol ons la etiopalogenia de los cuadros de diarrea aguda en lactantes.

Ltilizanmos para esta investigasión el medien selerlivo de: Troma y Deindriek preconizado por lis aulures ya mencionados. 10 .

\section{MATERIAL Y METODO}

Sir ennsideraron para nuestro estudion 100 lactantes elegiden al azar, ingresarlom al Hompital (Calvo Mackemna por cuadros de diarrea ayuda entre novie'mbre de 1978 y febtero de 1979, a los rekale's st les lemin una muestra de deponjuin diaria, duranle" 
las primerus dias de ingreso, cein un promediode 1.4 muestras por pasiente.

Eslas murstras lueron tomadas ton lirula de madera directamente elel pañal o a 1ravés de sonda rectal e introducida de inmediat" en un medin de transponte. ol de Cary Blair. Se intalizarem un total de 140 muestras.

La deposicion fue sembrada directamente en tredius selectiven Agar $\$ S$ y MC Conkey y además se introdujobla tirula en un tubocon $10 \mathrm{ml}$., de medio de Poma y Deimdriek, (Buffer fosfatu salino $0.067 \mathrm{M} \mathrm{pH}$ 7.6), en el cual se mantuvo durante: 21 dias a 4" $C$. Despues de esto periodo se efectuarmin traspasos a platas de Agar SS y Mc Conckey, que se incubaron 18 horas a $37^{\prime \prime} \mathrm{C}$. y se observarun 48 horas a temperatura ambiente. Se efectuó estudio biounimice de las cobonias lartusas negativas en los siguientes medius diferenciales: TSI. I,IA. MIO, citrato de Simmons y caldo urea; repicándose entre 3 a 5 solonias por plara.
La única cepa con caracteristicas de Yersinia enlerorolitica aislaula se envioj para sid confirmación al [nstitute Baveteriolégic'o ale Chile. el cuat a su ve'z. la refiriíal lostituto Pasteur de Paris. organismo yue

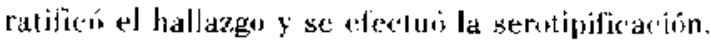

\section{RESULTADO}

La tabla N." l, ell xue se analizan los resultados del estudio bacteriologico de las deposiciones dirigido a la pezquisa de Yersinia enterocolítica, muestra que la siembra directa fue negativa en todos los casıs que se aisló una cepa de resinia enterocontitica en un larlante después de 21 días de incubación en el medio de Toma y Deindriek a partir de la placa de Agar Mc Conkey, lo que constituye el 17 de los casus estudialios y el $0.71 \%$ de las muestras.

En la tabla $\mathbf{N}$." 2 están registradas las curacterísticas bioquímicas de la cepa de Yersinja enterocolítica aislada.

\section{Tabla N. 1}

Aislamiento de Yersinia enterocolítica a partir de coprocultivos en lactantes con diarrea aguda. Hosp. Calvo Mackenna. 1979

\begin{tabular}{|c|c|c|c|c|}
\hline & $\begin{array}{l}\text { N." casos } \\
\text { estudiados }\end{array}$ & $\begin{array}{l}x . y \% \text { cosos } \\
\text { con Yersinia }\end{array}$ & $\begin{array}{l}\text { N:" muestras } \\
\text { estudiadas }\end{array}$ & $\begin{array}{l}\text { Ot mutestras con } \\
\text { aisl. Yersinia }\end{array}$ \\
\hline $\begin{array}{l}\text { A) Siembra directa } \\
\text { Agar SS } \\
\text { Agar Mc Con- } \\
\text { key }\end{array}$ & 100 & 0 & 140 & 0 \\
\hline $\begin{array}{l}\text { B) Enriquecimien- } \\
\text { to } 21 \text { ds. medio } \\
\text { 'loma Deindriek } \\
\text { Agar SS } \\
\text { Agar Mc Con- } \\
\text { key }\end{array}$ & 100 & $\begin{array}{c}0 \\
1\langle 1 \%) \\
1(1 \%)\end{array}$ & & $\begin{array}{c}0 \\
1 \\
1(0.71 \%)\end{array}$ \\
\hline
\end{tabular}

Tabla N.*2

Características bioquímicas Cepa y Enterocolítica aislada en coprocultivo Hosp. Calvo Mackenna 1979

\begin{tabular}{llll}
\hline Glucosa & + & Movilidad & $+t^{0}$ amb. \\
Lactosa & + tardia y débil & Oxidasa & - \\
Sacarosa & + & Lisina & - \\
Sorbitol & + & Arginina & - \\
Arabinusa & - & Ornitina & - \\
Ratinosa & - & Urea Christensen & + \\
Manitol & + & Indol & + débil \\
Ramnosa & - & H2S & + débil \\
Nitrato & $:$ reduce & Citrato Simmons & - \\
O/F & $:$ A/A & Malonato & - \\
\hline
\end{tabular}




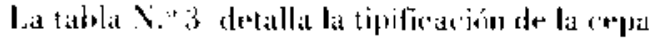
de Yersinia enteracolitica electuada en el lnstiluto bastem de Paris.

Tabla N.$^{0} 3$

Serotipiticación de cepa de Yersinia enterocolitica aislada en lactante con diarrea aguda. Instituto Paster, Paris

\section{Especie Quimiotipo Sero grupo Lysotipo}

Yersinia

$\begin{array}{llll}\text { enterocolítica } & 1 & 0: 7.8 & \mathrm{x} \mathrm{z}\end{array}$

En la tabla $\mathrm{N} . " 4$ pudenus observar las concentraciones inhibilorias minimas de 5 antimicrobianos frente a la cepa de Yersinia enterocolitica. De acuerdo a estos resuliados y en relacioin a los niveles plasmáticos que alcanzan estos antibioticos. la cepa resultio sensible a tedos ellis.

\section{Tabla N. ${ }^{\circ} 4$}

Sensibilidad in vitro de la cepa de Y. enterocolítica a 5 antimicrobianos. Hosp. C. Mackenna 1979

\begin{tabular}{ll}
\hline Antimicrobiano & CIM mcg/ml \\
\hline Ampicilina & 10 \\
Amoxicilina & 10 \\
Cotrimoxazole & 1.25 \\
Cloramfenicol & 5 \\
Gentamicina & 0.3 \\
\hline
\end{tabular}

La tabla N." 5. muestra las principales caracteristicas clínicas del cuadro diarreico que presentí esta lactante en que se aisló Yersinia enterncolítica.

\section{Tabla N. ${ }^{\circ} 5$}

Características del cuadro clínico asociado al aislamiento de Yersinia enterocolítica. Hosp. Calvo Mackenna. 1979

\begin{tabular}{ll}
\hline L.V.V. & : Sexo + Edad: 2 meses \\
\hline Enf. actual & : 1 dia con diarrea y vómitos. \\
Evolución & Deposiciones líquidas con \\
& mucus, 6al día, con compromi- \\
& so de sensorio. \\
& Fiebre: $37,5^{\circ} \mathrm{C}-38^{\circ} \mathrm{C}$ tres \\
& días duración. \\
& Deshidratación: moderadian un \\
& día duración. \\
& Exantema: no
\end{tabular}

Tratantuiento

: Amoxicilina 50 $\mathrm{gr} \times \mathrm{kg}-\mathrm{p} \times$ dia c/8brs, $x$ 5 ds. vía or:al, con buleind respuesta.

Latbonatorio:

Hemogramia

: Hto. $32 \% \quad \mathrm{Hb} 10.8 \%$

Leucocitos: 1 l.500 Eos 1 Bac.

Nent 43 Linto 50 Mono 5

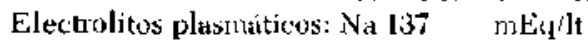

k 3.1 mEqijt

C) 98 mEqiit

Parasitólogico deposiciones: Vegativo

Coprocultivo: Yersinia enterocolitica

\section{COMENTARIO}

El mérito de nuestra investigación radica en que nueslros resultados corresponden al primer aislamiento de Yersinia enterocolítica perfectamente comprobado, realizado en patolog̣a infantil en nuestro país.

En esta lactante, en la cual se aislí Yersinia enterecolitica del coprocultivo, me se demustró coexistencia de otro bacterio enteropatógeno. ni tamporo de parúsitos intestinales. Presentó un cuadro que en lineas generales curresponde a lo observado en otros paisesist con depusicienes liquidas. mucosas frecuentes. acompanado de vími10s. (a) fiebre y comprumiso sensurial. Yersinia entercesolitica no se ha demostrado capaz de producir sindrome disentérico.

En nuestra paciente. no obstante. no observamos la aparición de vingún lipo de exantema en el curso de la diarrea, sintuma gue con alguna frecuencia suele acompañar a las gastronteritis provocadas por Yersinia y que debe hacer suspe"har dicha etiologia, pero el cual por supuesto no necesariamente está presente en el 100\% de lis parcientes. '.5)

En el presente raso desde el punto de vista clinice se planteó una shigellosis $y$ se trato la paciente con Amoxicilina, cun la cual se observó una buena respuesta ya que al tercer día de tratamiento las depusiciones se normalizaron y la niña mejori notablemente.

Felizmente para esta lactante, el estudio posterior de la cepa de Yersinia demostró una muy buena sensibilidad in vitro frente a Amoxicilina. Comunicaciones extranjeras en las cuales se ha podido estudiar un número mayor de cepas demuestran que Yersinia enterocolítica. en general, una buena sensibilidad in vitro frente a un gran número de antimirrubianus. ' 11 ,

La metodologia aplicada en este estudio que 
exige una incubación previa de 21 dias. solamente es d. rtilidad en el aspectu etiológico, pert nu constituye ninguna ayuda para el maneju clinico terapeutico del pariente. Desgracradamente la biologia pecouliar de este bacterio no farilita su desarroflo inicial a partir de muestras patoligic'as en los plazos habituales observados ra otros mic ruorganismos. por la menos es lo que sucede en los medios de: cultivo utilizados normalmente para realizar roproxultivis. Sin embargo. despuris del primer aistamiento $s$ a cultivo ulteriur en el laburatorio es fácil y crece a las 18 horas de imoubacion.

Fin el futuro será neecsario desarrollar ticnicas de altivo que permitan un aislamiento thás répide de la yersinia para contar con infurmación etiulógica uportuna que permita mejor manejo de éstos pacientes.

Sii bien la incidencia de Yersinia enterocolítica en cuadros de diarrea aguda en nuestro medir es baja, debemus tenerla cn mente, purque al tratarse de urid zoonosis en cualquier momento puede provocar brotes epidćmicos, dependiendo de la importancia y proyecciones que pueda alcanzar el reservorio animal en nuestra comunidad en el momento dads.

Ademas, no olvidemes que estamus re cihirndo ronstantemente importaciones de alimentos de diversos países con los cuales eventualmente podráamos estar ingresando bacterias exóticas. entre ellas Yersinia enterocolitica.

\section{CONCLISION}

Estos resultados constituyen el primer aislamisnto en Chile, confirmado, de patologia infantil provicada por Yersinia enterocolítica, bacteria que tendria en nuestro medio una ineidencia todavía baja II\%) como caltsante de diarrea aguda en lactantes.

\section{AGRADECIMIENTOS}

Nuestroa agradecimientos al Dr. W. Lederman, Jefe del Depto. de Adiestramiento del Instituto Bacteriológic'n de Chile, por su colaberación en la identificación de la cepa.

\section{RESUMEN}

Con el própusito de investigat lat incidencia de
Yersinia enterocolítica en cuadros de diarrea agruda, se estudiaron 100 lactanles que ingresaron pur esd patología al Hospilal Calvo Mackenna.

$A$ cada paciente se le tomi una o dos muestras de depusicion que fueron sembradas en Agar SS, Me Conkey y paralelamente en un medio selectivo para Yersinia Toma y Deindriek, el cual se incubó durante 21 dins a $4^{\prime \prime} \mathrm{C}$.

De los 100 pacientes estudiados. en uno de ellos, el $1 \%$, se aisió Yersinia enterocolitica a partir det medio de Toma y Deindriek. La cepa fue ('onfirmada por el Instituto Pasteur de París $y$ constituye el primer aislamiento de Yersinia en patología infantil en Chile.

El abilisis de las caracteristicas del cuadru clínicus nu mostri aspectus relevantes.

\section{REFEREXCIAS}

${ }^{1}$ M.M.W,R. - Yersinia enterocolítica. Outbreak, Sew York. Vol. 26, N."753, 1977.

2 Toma S., Loefleur L.: Suryey on the incidence of yersinia entercxcolítica infection in Canada. A ppl. Microbiol. 28: 469$473,1974$.

${ }^{\top}$ Brumer D. J., Steigerwait, A. G.; Fatco, D. Weater R.; Charecterization of yersinia enterocolitica and yersinia pseudatuberculosis by deoxyribonucleic acid Hydrization ayd by bioclientical reactions. Int. J. Syst. Bact. Vol. 26 N." 2, Lisi-94, 1976.

4 Buthman, R. E.; Gibbson, N. E.: Bergey's Mamusl or Determinative bacteriology 8t. ed. 1974.

5 M.M.W.R.: Yersinia enterocolitica infections. Georgia Ctah, Vol. 24 N. $16,147,1975$.

${ }^{6}$ sommersmith H. C.; Wedver, R. E.: Yersinia enterocolitica. ‥ Engl. J. Med. Vol. 283: 1.468, 1970.

I Sommersmith, A. C.: Bacteremic with and without meningitis due to yersinia enterocolitica, E. tardia, C. Terrigera and P. Maltuphilia. Aim. N.Y. Acad. Sci. 174: 486-502, 1970.

${ }^{8}$ Fatca, D. P.; Euing, W. H., Davis, B. R., y Herman, G. J.. Yersioin entenocolitica e yersinia pseudotuberculosis caracteristicas netabólicas e identificau pres untiva. Presentado al Vil Cungreso Latiusaunericamn de Microbiología, Buenus Aires, Argentinis 1977.

Y.Atonso, O,; Zanora, J,; Saa, A.; Huñuz, R.: Aislatiento de Yersinia enterocolítica en ratones silvestres. Presentada a la Jortiada Anual de la Asociación Chilena de Aicrobiología. Santiago, Chile, 1976.

I0 Carcia, J-; Maddonado, A.; Lobos, $T_{\text {.: }}$ Asslamiento de Yersinia enterocolitica en intestino humano adulto. Boletin Instituto Bacteriológico de Chile. Vol. 20, N." 1, 1979.

11 Fatew, D. P.; Famer, IJ.; Dotiel Jr., V. R.: Yersinia enteracolitiua e Yersinia pseudotubercildosis y sensibilidad a druga. Presentado al VIl Congreso Latinoamericano de Microbiologia, Buenos Aires, Argentina, 1977. 